\title{
Automatic diagnosis of strawberry water stress status based on machine vision
}

\author{
Han $\mathrm{Li}^{1}$, Jian Yin ${ }^{1}$, Man Zhang ${ }^{1}$, Nick Sigrimis ${ }^{2}$, Yu Gao ${ }^{3}$, Wengang Zheng ${ }^{4}$ \\ (1. Key Laboratory for Modern Precision Agriculture System Integration Research, Ministry of Education, China Agricultural University, \\ Beijing 100083, China; 2. Department of Natural Resources Management and Agricultural Engineering, Agricultural University of Athens, \\ Athens 11855, Greece; 3. School of Electronic and Information Engineering, Hebei University of Technology, Tianjin 300401, China; \\ 4. National Research Center of Intelligent Equipment for Agriculture, Beijing 100097, China)
}

\begin{abstract}
Water stress status of plants is very important for irrigation scheduling. However, plant water stress status monitoring has become the bottleneck of irrigation scheduling. In this study, an automatic water stress status monitoring method for strawberry plant was proposed and realized using combined RGB and infrared image information. RGB image and infrared images were obtained using RGB digital camera and infrared thermal camera, which were placed in a fixed shell in parallel. In the first experimental stage, three kinds of water stress treatments were carried out on three groups of strawberry plants, and each group includes three repetitions. Single point plant temperature, dry surface temperature, wet surface temperature were measured. In the second experimental stage, the infrared and visible light images of the canopy leaves were obtained. Meanwhile, plant temperature, dry surface temperature, wet surface temperature, and stomatal conductance were measured not only for single point but also for plant area temperature measurement. Fusion information of infrared image and visible light image was analyzed using image processing technology, to calculate the average temperature of plant areas. Based on single point temperature, area temperature, dry surface temperature and wet surface temperature of the plant, single point crop water stress index (CWSI) and area CWSI were calculated. Through analysis of variance (ANOVA), the experimental results showed that CWSI measured for plants under different treatments, were significantly different. Through correlation analysis, the experimental results showed that, determination coefficient between area CWSI and the corresponding stomatal conductance of three strawberry groups were $0.8834,0.8730$ and 0.8851 , respectively, which were larger than that of single-point CWSI and stomatal conductance. The results showed that area CWSI is more suitable to be used as the criteria for automatic diagnosis of plants.
\end{abstract}

Keywords: automatic diagnosis, water stress, crop water stress index, machine vision, strawberry

DOI: $10.25165 /$ j.ijabe. 20191201.4293

Citation: Li H, Yin J, Zhang M, Sigrimis N, Gao Y, Zheng W G. Automatic diagnosis of strawberry water stress status based on machine vision. Int J Agric \& Biol Eng, 2019; 12(1): 159-164.

\section{Introduction}

Water resource shortage has become the primary factor limiting agricultural development. Controlling irrigation throughout the growth season of plants is a requisite for the sustainable development of the agriculture.

Irrigation scheduling can be made based on at least three methodologies $^{[1]}$. The soil water content based approach is based on the direct measurement of soil moisture content. This method can start and stop the irrigation according to the current water content in the soil, which is widely applied in automation system due to its easy application and practice ${ }^{[2-5]}$. However, because it is difficult to put the water content measurement sensor at the plant root position where can respond the water status of it, the accuracy

\section{Received date: 2018-04-03 Accepted date: 2018-09-10}

Biographies: Han Li, PhD, research interest: agricultural information technology, Email: cau_lihan@cau.edu.cn; Jian Yin, Graduate student, research interest: agricultural information technology, Email: 465170245@qq.com; Nick Sigrimis, PhD, research interest: precision agriculture, Email: ns@aua.gr; Yu Gao, Graduate student, research interest: agricultural information technology, Email: 465170245@qq.com; Wengang Zheng, PhD, research interest: agricultural information technology, Email: zhengwg@ nercita.org.cn.

*Corresponding author: Man Zhang, PhD, research interest: agricultural information technology. China Agricultural University, No.17 Qinghua East Road, Beijing 100083, China. Email: cauzm@cau.edu.cn. of this method usually cannot meet the requirement.

A second method is soil water balance based method, which uses meteorological information to calculate the water need of the plant. This method calculates plant water evaporation $\left(\mathrm{ET}_{\mathrm{C}}\right)$ according to the meteorological information, and controls the irrigation amount based on $\mathrm{ET}_{\mathrm{C}}{ }^{[6]}$. Since this method needs rainfall, solar radiation, wind speed, wind direction, air humidity, atmosphere as input, and the plant coefficient needs to be estimated through the whole growth season, it is easy to cumulate large error. This method also requires professional personal to calculate and maintain the measurement device regularly, which limited its application.

The third approach is to calculate the water need of the plant indirectly based on the plant water stress induction. This method measures the stress of plant itself, using its physical reaction to water stress to calculate water need of the plant, and then make irrigation decision, which is promising for precise irrigation scheduling ${ }^{[7]}$. Methods developed for water stress reaction of plant can be classified into two categories, which were plant tissue water status detection and plant physiological reaction detection. Stomatal conductance (Gs) and leaf temperature are two kinds of mostly used indicator for plant physiological reaction detection. However, the detection process of Gs is complicated, time consuming, easily to damage the plant and can only detect single leaf per measurement. Compared with Gs detection, plant 
temperature detection is much more flexible, especially when using thermal infrared camera, which makes the remote and rapid measurement of the plant water stress possible. Thermal infrared camera has become an ideal tool for temperature measurement for not only single point of a plant, but also crop parts within the thermal infrared image. Temperature measurement based on thermal infrared camera for plant water stress monitoring has become research focus over the past 30 years.

The direct measurement of the leaf temperature is sensitive to environment change, which will result in error when analyze the plant water stress status. Idso et al. ${ }^{[8]}$ proposed the crop water stress index (CWSI), which is a kind of normalized quantization parameter for plant water stress. To some extent, it overcomes the environmental change problem, and could reflect the water stress status of the plant. CWSI can be determined using three approaches. The first one is "empirical model", which is based on the relationship between canopy-air temperature difference (Tc$T a$ ) and air vapour pressure deficit (VPD) of a 'non-water-stressed baseline' (NWSB) ${ }^{[8]}$. The second approach is energy balance based, which requires net radiation and aerodynamic resistance factor as input, which made this method difficult to apply in practice $^{[9,10]}$. The third approach is reference based. This method directly use natural leaves ${ }^{[11,12]}$ or artificial reference ${ }^{[13,14]}$ to estimate the minimum and maximum temperatures, which reduces the error induced from wind speed, radiation and solar radiation change, and Gs the stomatal conductance $\left(\mathrm{mmol} / \mathrm{m}^{2} \cdot \mathrm{s}\right)$. CWSI can be calculated through Equation (1):

$$
C W S I=\frac{T_{l e a f}-T_{w e t}}{T_{d r y}-T_{w e t}}
$$

where, $T_{d r y}$ and $T_{\text {wet }}$ are surface temperature of the dry and wet reference targets $\left(\mathrm{K}\right.$ or $\left.{ }^{\circ} \mathrm{C}\right)$, and $T_{\text {leaf }}$ is the temperature of the measured leaf. Compared with other two methods, this method is easier to practice. The reference based method is widely studied because it does not require environmental information as input $^{[15-18]}$.

To automatically extract area plant temperature, thermal infrared and visible information should be combined. Möller et al. ${ }^{[19]}$ manually chose control points in obtained thermal infrared and visible images using Matlab R13 software, and extracted area temperature of the grape plant after image matching, and CWSI of the plant area was then calculated. Raza et al. ${ }^{[20]}$ also used image processing software to process the thermal infrared and visible spinach images after they were obtained. Through using points manually chosen, thermal infrared image and visible image were successfully matched, which was a key step for the following water stress detection of the plant. To date, this reference based approach has not been widely applied in the field and help with the automatic irrigation scheduling yet. Major reasons are that plant area temperature cannot be automatically extracted from the thermal infrared image and it is unknown that how the area temperature of the canopy is superior to single point measurement of the leaf temperature.

In this article, a reference based automatic diagnosis method for plants was presented and evaluated. The specific objectives of this paper are as follows:

(1) to achieve automatic plant area temperature detection based on infrared image and visible light image,

(2) to conduct a comparative study on the correlation between single point water stress index and stomatal conductance, area water stress index and stomatal conductance, exploring how CWSI can be used in automatic diagnosis of crop water stress status.

\section{Materials and methods}

\subsection{Experiment design}

The experiment was conducted in Laboratory of National Engineering Research Center for Information Technology in Agriculture (NERCITA). The variety of strawberry was "Beijing Spring". The sample plants used in this study were planted in September 20th in Institute of Forestry and Pomology, Beijing Academy of Forestry Sciences. Before the experiment, the strawberry samples were fertilized and managed uniformly. Each strawberry plant was planted in a pot, the size of which is $12 \mathrm{~cm} \times$ $15 \mathrm{~cm}$, the substrates in it was peat and chicken manure, with a mix proportion of $5: 1$.

The whole experiment includes two stages. The first stage is to validate that if the leaf temperature could be used to detect strawberry water stress. Nine strawberry plants were transplanted to NERCITA in April 15th. These nine strawberry plants were divided into three groups. Group 1 was treated with standard watering, which means the soil moisture content was maintained at $35 \%$ to $45 \%$. Group 2 was treated with mild water stress watering, which means the soil moisture content was maintained at $25 \%$ to $35 \%$. Group 3 was treated with severe water stress watering, which means the soil moisture content was maintained at $15 \%$ to $25 \%$. After the first 5 days of different water treatment, they were used for data collection from April 20th to April 27th. From 9:00 am to $5: 00 \mathrm{pm}$ every day in the experimental period, soil moisture content, and single point leaf temperature of leaves were recorded hourly. In order to calculate the crop water stress index (CWSI) of leaves, beside actual leaf temperature, which was obtained using average temperature of three leaves of each plant, procedures were taken to detect temperatures of a wet leaf and a dry leaf. Wet leaf was made by spraying water on both sides of a leaf of the plant, then the temperature of this wet leaf was collected after $10 \mathrm{~s}$. Dry leaf was made by smearing a leaf with Vaseline on both sides, then the temperature of this dry leaf was collected after $10 \mathrm{~s}$.

In the second stage, another three strawberry plants were transplanted to NERCITA on June 12th. These three strawberry plants were used for data collection from June 17th to June 22nd. The difference between the second stage and the first stage was that, on June 22nd, stomatal conductance, both thermal infrared and visible images were obtained every hour between 9:00 am to 5:00 pm when collecting other data (soil moisture content, single point leaf temperature, wet leaf temperature and dry leaf temperature), to compare the water stress performance of area temperature and single point temperature, and develop an automatic diagnosis method for strawberry plant.

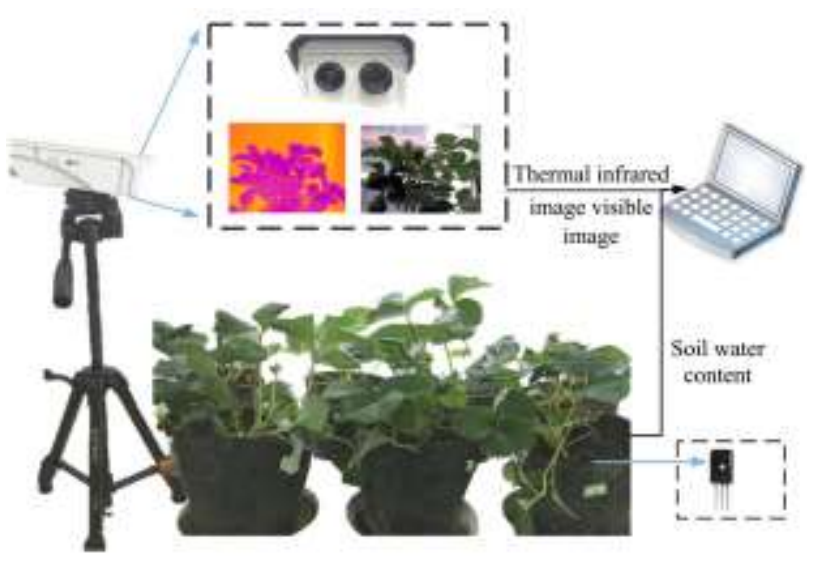

Figure 1 Experiment setup architecture: Imaging module with visible camera on the left, and the thermal infrared camera on the right 
The experiment setup is shown in Figure 1. A visible network camera and a thermal infrared camera were fixed in a shell in parallel, so that both visible image and thermal infrared image can contain overlapped field of view. The camera on the left is the visible light camera, and the one on the right is the thermal infrared camera. The visible network camera model is JA-791HRC (Jooan Science and Technology Co., Ltd., China), with resolution of $1280 \times 720$, power supply of $12 \mathrm{~V} / 2 \mathrm{~A}$, operating temperature of $-30^{\circ} \mathrm{C}-60^{\circ} \mathrm{C}$. The thermal infrared camera is Tau2 336 (FLIR systems, Inc., USA), with resolution of $256 \times 336$. The sensitivity of TauTM 336 camera is $0.05^{\circ} \mathrm{C}(50 \mathrm{mK})$, and the accuracy of TAU2-336 camera is $\pm 2{ }^{\circ} \mathrm{C}$ after calibration. Each strawberry plant pot had a soil water content sensor in it, the model of which is FDS100 (Beijing Lianchuang Siyuan technology Co., Ltd., China). The obtained images were analyzed using Visual Studio 2010. The stomatal conductance was measured using SC 1 steady state porometer (Meter Group, Inc., USA).

The water treatment of the strawberry plants was shown in Table 1. The soil moisture content change of strawberry plants is shown in Figure 2.

Table 1 Three water stress treatments of Strawberry plants

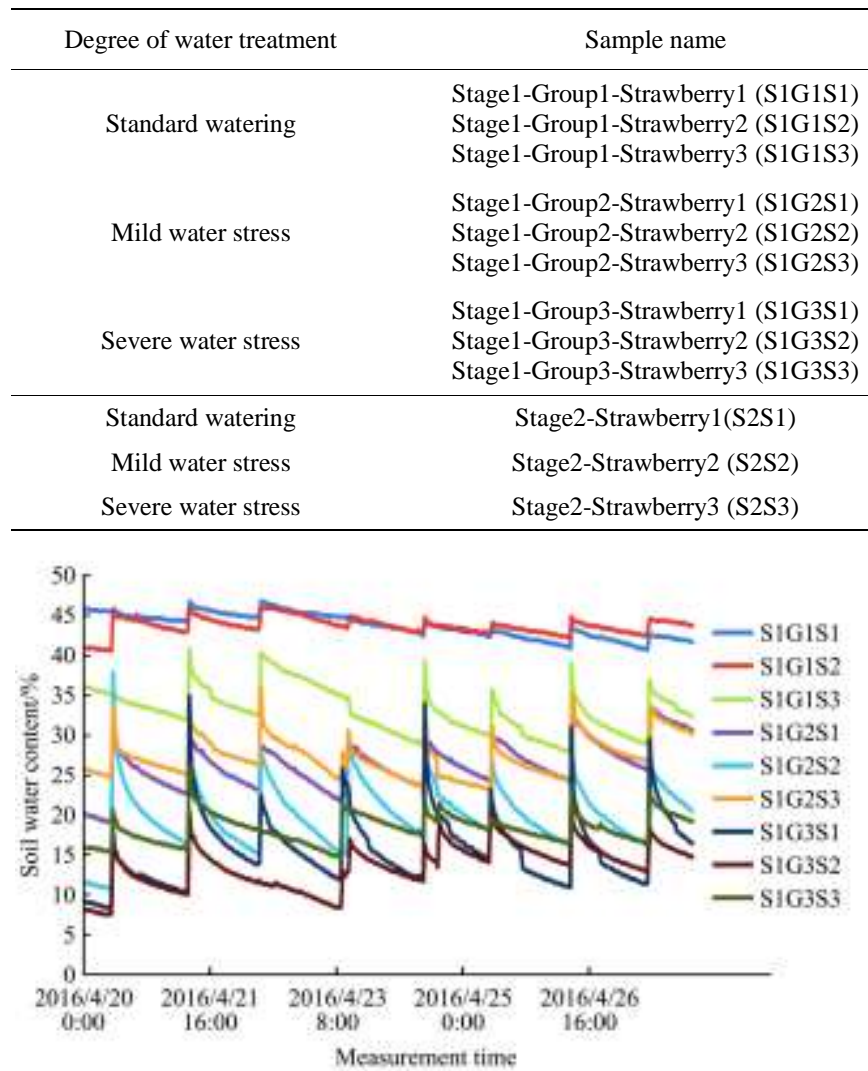

a. Soil water content change during stage 1 for nine strawberry plants
Treatment

Date

Soil moisture content was maintained at $35 \%-45 \%$

Soil moisture content was maintained at $25 \%-35 \%$

April 20-27

Soil moisture content was maintained at $15 \%-25 \%$

Soil moisture content was maintained at $35 \%-45 \%$

Soil moisture content was maintained at $25 \%-35 \%$

Soil moisture content was maintained at $15 \%-25 \%$

June 17-22

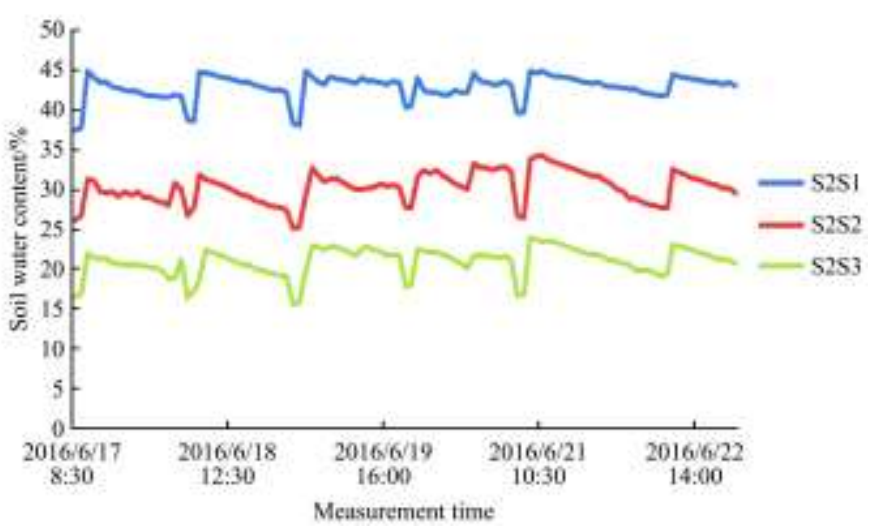

b. Soil water content change during stage 2 for three strawberry plants

Figure 2 Changes in water content of Strawberry during two experiment stage

\subsection{Phase consistency based automatic crop area temperature} extraction method

A phase consistency based automatic crop area temperature extraction method was developed and used in this study. The main challenge was automatically matching of the infrared image and visible image. Flow chart of the proposed automatic crop area temperature is shown in Figure 3. This paper firstly carried out phase consistency based edge detection for the two images ${ }^{[21]}$. Calculation of SURF feature descriptors is mainly divided into two steps: feature point detection and formation of feature point descriptor ${ }^{[22,23]}$. After obtaining feature points of the image and its descriptors by the method of SURF, the next step was to match feature points. Feature point match is divided into two steps. The first step is called "rough matching", which uses Euclidean distance as the similarity measure. It takes one interest point in thermal infrared image, and find out which point in visible image had nearest Euclidean distance, then it is flagged as a match point. The second step is to filter out the wrong matching points by the method of RANSAC (random sampling consensus) ${ }^{[24]}$. Affine transformation parameters can be calculated when the matching of the two images is more than 3. After affine transformation is carried out on the visible light image, the transformed infrared image is fused with the original visible image.

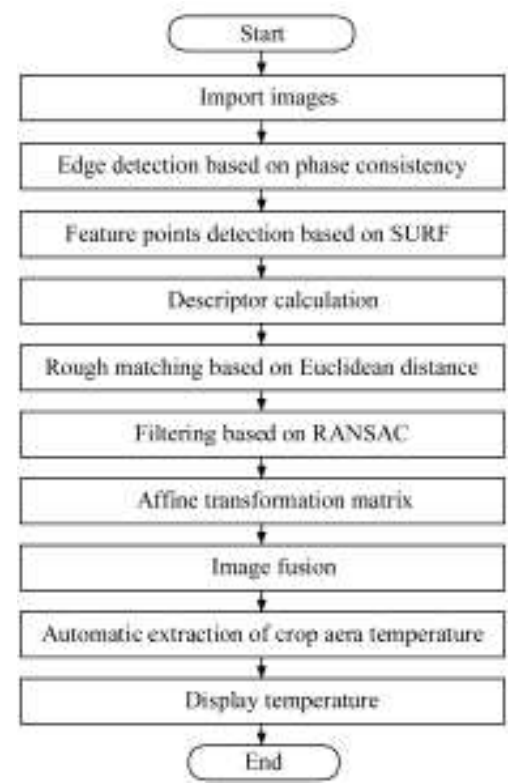

Figure 3 Flow chart of automatic matching algorithm for infrared image and visible image 
The purpose of automatic fusion of infrared and visible light images was to recognize the crop area in infrared image (Figure 4a) using the color information of visible image (Figure 4b). After the visible image was transformed based on Affine parameter (Figure 4c), the area of strawberry plant was segmented from the transformed image. As thermal infrared image and the visible

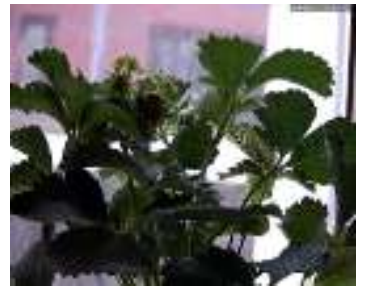

a. Visible light image

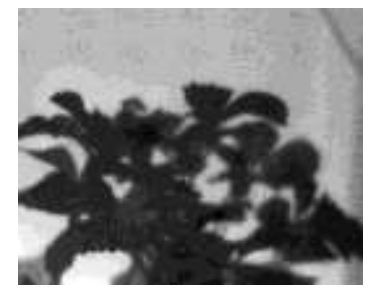

b. Infrared image

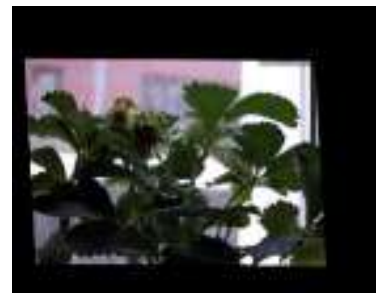

c. Transformed image based on Affine parameter image were matched, the plant area of the infrared image was extracted, according to the corresponding locations of the plant in visible light image, as shown in Figure 4d. Based on the infrared image, the temperature of the plant was analyzed, and the mean value of canopy temperature was obtained.

Figure 4 Plant area extraction from thermal infrared image

\section{Results and discussion}

Figure 5 shows the comparison of the daily mean temperature of the strawberry plants, which indicates that, with the increase of the water stress, the mean temperature value of the plants increases.

Table 2 shows results of single factor ANOVA of single point temperature of three groups of strawberries in stage 1 (values in the same column with the same letter are not significantly different at $p=0.05$ ). During the test, different water treatment resulted in significant differences in crop canopy temperature. There was significant difference between group 1 (standard watering strawberries 1-3) and group2 (mild stress of strawberry 4-6), and significant difference between group 1 and group 3 (the strawberry 7-9). However, the difference between group 2 and group 3 was not very significant. On April 27th, all three groups demonstrated significant difference.

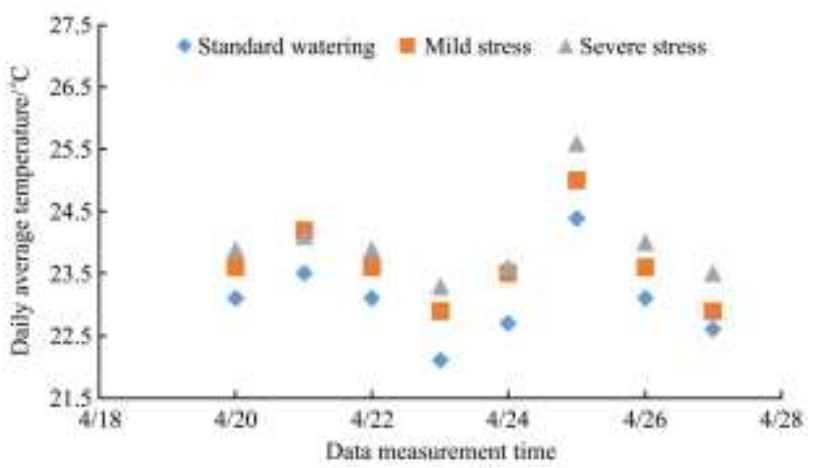

Figure 5 Daily mean temperature comparison of the strawberry canopies

Table 2 Results of single factor ANOVA of crop canopy temperature

\begin{tabular}{|c|c|c|c|c|c|c|c|c|}
\hline \multirow{3}{*}{ Process } & \multicolumn{8}{|c|}{ Temperature $/{ }^{\circ} \mathrm{C}$} \\
\hline & April 20th & April 21st & April 22nd & April 23rd & April 24th & April 25th & April 26th & April 27th \\
\hline & $\begin{array}{c}\text { Sample number } \\
\text { (63) }\end{array}$ & $\begin{array}{c}\text { Sample number } \\
\text { (45) }\end{array}$ & $\begin{array}{l}\text { Sample number } \\
\text { (63) }\end{array}$ & $\begin{array}{c}\text { Sample number } \\
\text { (36) }\end{array}$ & $\begin{array}{c}\text { Sample number } \\
\text { (45) }\end{array}$ & $\begin{array}{c}\text { Sample number } \\
\text { (45) }\end{array}$ & $\begin{array}{c}\text { Sample number } \\
\text { (45) }\end{array}$ & $\begin{array}{c}\text { Sample number } \\
(81)\end{array}$ \\
\hline Standard watering & $23.1 \mathrm{a}$ & $23.5 \mathrm{a}$ & $23.1 \mathrm{a}$ & $22.1 \mathrm{a}$ & $22.7 \mathrm{a}$ & $24.4 \mathrm{a}$ & $23.1 \mathrm{a}$ & $22.6 \mathrm{a}$ \\
\hline Mild stress & $23.6 \mathrm{~b}$ & $24.2 \mathrm{~b}$ & $23.6 \mathrm{~b}$ & $22.9 \mathrm{~b}$ & $23.5 \mathrm{~b}$ & $25 \mathrm{~b}$ & $23.6 \mathrm{~b}$ & $22.9 \mathrm{~b}$ \\
\hline Severe stress & $23.9 \mathrm{~b}$ & $24.1 \mathrm{~b}$ & $23.9 \mathrm{~b}$ & $23.3 \mathrm{~b}$ & $23.6 \mathrm{~b}$ & $25.6 \mathrm{~b}$ & $24.0 \mathrm{~b}$ & $23.5 \mathrm{c}$ \\
\hline
\end{tabular}

Compared with the absolute value of the temperature of the crop, crop water stress index (CWSI) more reliable due to that it can remove the influence of ambient change. CWSI was calculated using Equation (1), by calculating the difference between the crop canopy temperature and the wet reference surface temperature, then divided by the dry and wet reference surface temperature, the CWSI of different plants were obtained. The results of single factor ANOVA analysis of CWSI is shown in Table 3 (values in the same column with the same letter are not significantly different at $p=0.05$ ). As can be seen from Table 3, with the increase of stress, the mean value of CWSI becomes higher. By single factor ANOVA analysis, it is found that there was significant difference between group 1 and group 3 on all the experiment days. Also Figure 6 shows the determinate coefficient (determinate coefficient can be expressed by $R^{2}$ ) between CWSI and soil water content measured at $3 \mathrm{pm}$ on April 20th, 24th, and 27 th was between 0.6074 and 0.8 , which proved that CWSI could reflect the state of crop water stress. On April 20th, 23rd, 25th, 26th, 27th, there was a significant difference in CWSI between the three group 1 and the group 2. However, on the April 21st, 22nd and 24 th, there were no obvious significant difference. Between group 2 and group 3, there was no obvious significant difference on April 20th, 23rd, 25th and 26th. The reason might be that individual plant sampling of the sample was not enough, the three leaf temperature could not represent the whole plant temperature conditions, the problem could be solved by increasing the number of sample methods to solve through extracting the plant area using thermal infrared image and visible image.

During experiment stage 2, single factor ANOVA analysis of single point CWSI was also conducted for three strawberries, the results of which is shown in Table 4 (values in the same column with the same letter are not significantly different at $p=0.05$ ). By single factor ANOVA analysis, it is found that there is significant difference between strawberry 1 and strawberry 3 on all the experiment days. This result is consistent with stage1. 
Table 3 Results of single factor ANOVA of CWSI

\begin{tabular}{|c|c|c|c|c|c|c|c|c|}
\hline \multirow{3}{*}{ Process } & \multicolumn{8}{|c|}{ CWSI } \\
\hline & April 20th & April 21st & April 22nd & April 23rd & April 24th & April 25th & April 26th & April 27th \\
\hline & $\begin{array}{l}\text { Sample number } \\
\text { (63) }\end{array}$ & $\begin{array}{l}\text { Sample number } \\
\text { (45) }\end{array}$ & $\begin{array}{l}\text { Sample number } \\
\text { (63) }\end{array}$ & $\begin{array}{l}\text { Sample number } \\
\text { (36) }\end{array}$ & $\begin{array}{l}\text { Sample number } \\
\text { (45) }\end{array}$ & $\begin{array}{c}\text { Sample number } \\
\text { (45) }\end{array}$ & $\begin{array}{l}\text { Sample number } \\
\text { (45) }\end{array}$ & $\begin{array}{c}\text { Sample number } \\
(81)\end{array}$ \\
\hline Standard watering & $0.56 \mathrm{a}$ & $0.59 \mathrm{a}$ & $0.70 \mathrm{a}$ & $0.76 \mathrm{a}$ & $0.78 \mathrm{a}$ & $0.65 \mathrm{a}$ & $0.74 \mathrm{a}$ & $0.64 \mathrm{a}$ \\
\hline Mild stress & $0.66 \mathrm{~b}$ & $0.65 \mathrm{ac}$ & $0.76 \mathrm{ac}$ & $0.85 \mathrm{~b}$ & $0.82 \mathrm{ac}$ & $0.75 \mathrm{~b}$ & $0.80 \mathrm{~b}$ & $0.89 \mathrm{~b}$ \\
\hline Severe stress & $0.70 \mathrm{~b}$ & $0.70 \mathrm{bc}$ & $0.79 \mathrm{bc}$ & $0.88 \mathrm{~b}$ & $0.85 \mathrm{bc}$ & $0.82 \mathrm{~b}$ & $0.83 \mathrm{~b}$ & $0.90 \mathrm{c}$ \\
\hline
\end{tabular}

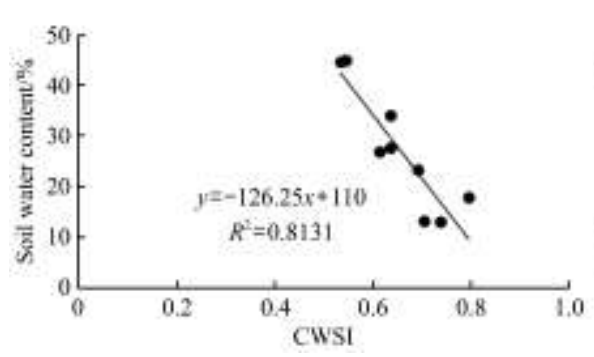

a. April $20^{\text {th }}$

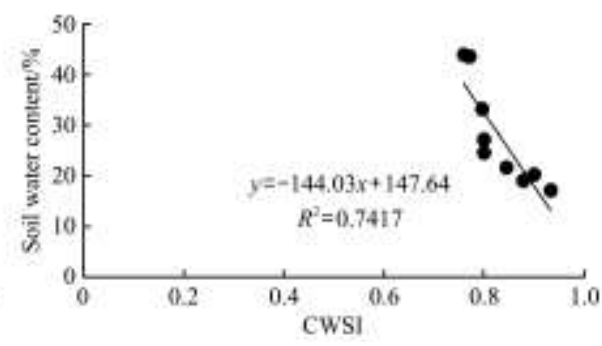

b. April $24^{\text {th }}$

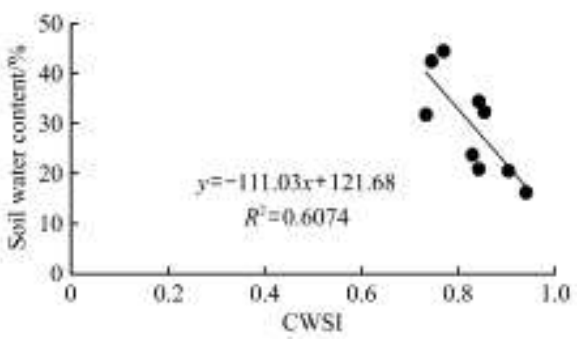

c. April 27 th

Figure 6 Correlation between CWSI and soil water content measured at 3 pm on April 20th, 24th, and 27th

Table 4 Results of single factor ANOVA of CWSI

\begin{tabular}{|c|c|c|c|c|c|c|}
\hline \multirow{3}{*}{ Process } & \multicolumn{6}{|c|}{ CWSI } \\
\hline & June 17th & June 18th & June 19th & June 20th & June 21st & June 22nd \\
\hline & Sample number (27) & Sample number (27) & Sample number (27) & Sample number (27) & Sample number (27) & Sample number (27) \\
\hline Enough water & $0.81 \mathrm{a}$ & $0.73 \mathrm{a}$ & $0.68 \mathrm{a}$ & $0.80 \mathrm{a}$ & $0.74 \mathrm{a}$ & $0.72 \mathrm{a}$ \\
\hline Mild stress & $0.87 \mathrm{ac}$ & $0.79 \mathrm{ac}$ & $0.77 b$ & $0.87 b$ & $0.83 b$ & $0.79 b$ \\
\hline Severe stress & $0.91 \mathrm{bc}$ & $0.84 \mathrm{bc}$ & $0.88 \mathrm{c}$ & $0.92 \mathrm{c}$ & $0.93 c$ & $0.88 \mathrm{c}$ \\
\hline
\end{tabular}

In order to increase the number of samples, this paper studied automatic temperature acquisition method of the entire crop canopy area based on the infrared and visible images. Between 9:00-17:00 in June 22, 2016, nine infrared images and nine visible light images of each strawberry canopy were collected every hour. And through automatic matching algorithm based on phase consistency, crop canopy area at different time and the

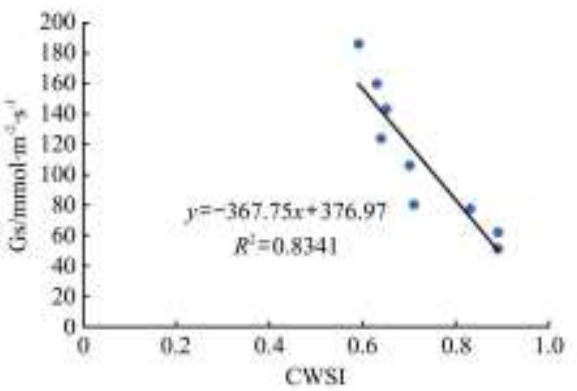

a. Correlation between single point CWSI and Gs of Strawberry 1

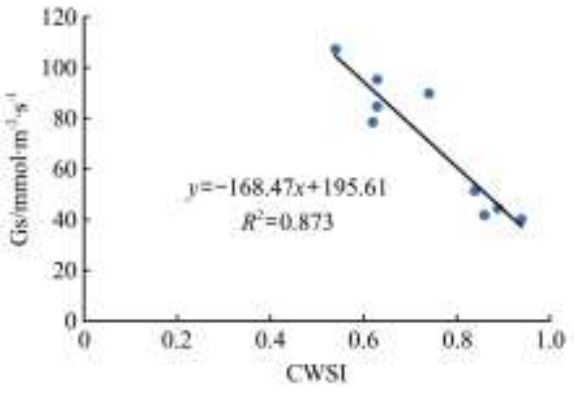

d. Correlation between area CWSI and Gs of Strawberry 2

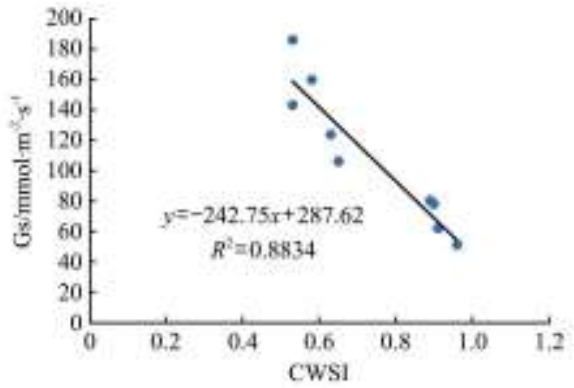

b. Correlation between area CWSI and Gs of Strawberry 1

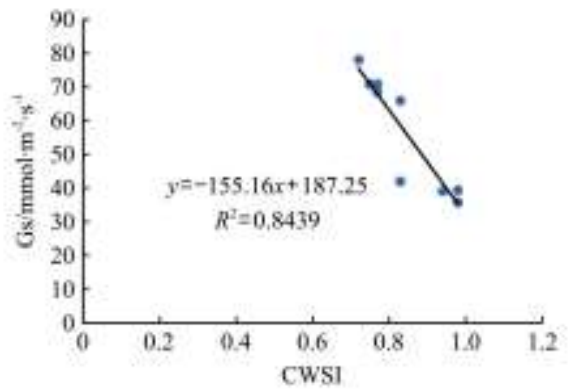

e. Correlation between single point CWSI and Gs of Strawberry 3 corresponding average temperature were obtained. Stomatal conductance was also measured immediately after images were obtained. The relationships between CWSI and stomatal conductance were shown for single point and area temperature, are shown in Figure 7. It could be observed that the determinate coefficient between area CWSI and stomatal conductance (stomatal conductance was expressed using "Gs") is higher than that between

Figure 7 Relationship between water stress index (CWSI) and stomatal conductance in strawberry plants 
single point CWSI and stomatal conductance in general. Compared of strawberry 1 and strawberry canopy area 1 , strawberry 2 and strawberry canopy area 2, strawberry 3 and strawberry canopy area 3 , it is found that determinate coefficient of single strawberry leaf is relatively lower compared with that of plant area. But overall, the correlation of $R^{2}$ is larger than 0.8 for both single strawberry leaf and canopy area. And in general, from the relationship graph of CWSI and stomatal conduction, it can be seen that determination coefficient of plant area is larger than that of single point of strawberry leaf. This result demonstrated that both single point and area CWSI could reflect the water stress status of strawberry plant. Using plant area CWSI based on infrared image and visible light image, the result was more accurate.

\section{Conclusions}

In this research, the automatic diagnosis method of crop water stress has been studied. The main results were summarized as following:

(1) The infrared image and visible light image information were fused based on machine vision technology, and the automatic acquisition of the crop area temperature was realized.

(2) The experimental results showed that the temperature and corresponding CWSI of strawberry crops, with different water treatments, had significant differences. The correlation between single point CWSI and stomatal conductance, area CWSI and stomatal conductance was further studied. The results showed that the correlation value between area CWSI and the stomatal conductance was higher than that of the single point CWSI and the stomatal conductance. It shows that area CWSI is feasible for crop water stress status monitoring, and it can be used as an important reference index for crop water stress assessment.

The system can be used to monitor the plant growth status easily and quickly. It can also acquire temperature continuously, non-destructively and automatically. The realization of automatic diagnosis of water stress detection based on machine vision is helpful to improve accuracy of the irrigation decision.

\section{Acknowledgements}

The project was supported by the National Natural Science Fund (Grant No. 31701319), National Key Research and Development Program (Grant No. 2016YFD0200602), Marie Curie project entitled "A Traceability and Early warning system for supply chain of Agricultural Product: complementarities between EU and China" (TEAP, EU-CHINA project PIRSES-GA-2013612659), and CAU Special funds for basic research and business expenses (2017QC020).

\section{[References]}

[1] Zhang Q, Pierce F J. Agricultural automation: Fundamentals and practices. CRC Press, 2013.

[2] Evett S R. Soil water and monitoring technology. In: R. J. Lascano and R .E. Sojka, editors, Irrigation of Agricultural Crops. Agron. Monogr. 30. 2nd ed. ASA, CSSA, and SSSA, Madison, WI. pp.25-84.

[3] Sui R, Fisher D K, Barnes E M. Soil moisture and plant canopy temperature sensing for irrigation application in cotton. Journal of Agricultural Science, 2012; 4(12): 93-105.

[4] Raper T B, Henry C G, Espinoza L, Ismanov M, Oosterhuis D M. Response of two inexpensive commercially produced soil moisture sensors to changes in water content and soil texture. Agricultural Sciences, 2015; 6(10): 1148-1163

[5] Müller T, Bouleau C R, Perona P. Optimizing drip irrigation for eggplant crops in semi-arid zones using evolving thresholds. Agricultural Water Management, 2016; 177: 54-65

[6] Allen R G, Pereira L S, Raes D, Smith M. Crop evapotranspiration. FAO Irrigation and Drainage Paper 56. Rome: FAO, 1999.

[7] Jones H G. Plant water relations and implications for irrigation scheduling. Acta Horticulturae, 1990; 278: 67-76.

[8] Idso S B, Jackson R D, Pinter P J, Reginato R J, Hatfield J L. Normalizing the stress-degree-day parameter for environmental variability. Agricultural Meteorology, 1981; 24: 45-55.

[9] Jackson R D, Idso S B, Reginato R, Pinter P J. Canopy temperature as a drought stress indicator. Water Resources Research, 1981; 17: 1133-1138.

[10] Jackson R D, Kustas W P, Choudhury B J. A re-examination of the crop water stress index. Irrig Sci, 1988; 9: 309-317

[11] Jones H G, Stoll M, Santos T, de Sousa C, Chaves M M, Grant O M. Use of infrared thermography for monitoring stomatal closure in the field: application to grapevine. Journal of Experimental Botany, 2002; 53: 2249-2260.

[12] Leinonen I, Jones H G. Combining thermal and visible imagery for estimating canopy temperature and identifying plant stress. Journal of Experimental Botany, 2004; 55(401): 1423-1431.

[13] Meron M, Tsipris J, Charitt D. Remote mapping of crop water status to assess spatial variability of crop stress. Precision Agriculture. Proceedings of the 4th European Conference on Precision Agriculture, Berlin, Germany. Wageningen: Academic Publishers, 2003; pp.405-410.

[14] Maes W H, Baert A, Huete A R, Minchin P E H, Snelgar W P, Steppe K. A new wet reference target method for continuous infrared thermography of vegetations. Agricultural and Forest Meteorology, 2016; 226: 119-131.

[15] Roy S, Ophori D. Estimation of crop water stress index in almond orchards using thermal aerial imagery. Journal of Spatial Hydrology, 2014; 12(1)

[16] Bellvert J, Marsal J, Girona J, Zarco-Tejada P J. Seasonal evolution of crop water stress index in grapevine varieties determined with high-resolution remote sensing thermal imagery. Irrigation Science, 2015 33(2): 81-93.

[17] Bellvert J, Zarco - Tejada P J, Marsal J, Girona J, González - Dugo V, Fereres E. Vineyard irrigation scheduling based on airborne thermal imagery and water potential thresholds. Australian Journal of Grape and Wine Research, 2015.

[18] Gerhards M, Rock G, Schlerf M, Udelhoven T. Water stress detection in potato plants using leaf temperature, emissivity, and reflectance. International Journal of Applied Earth Observation and Geoinformation, 2016; 53: 27-39

[19] Möller M, Alchanatis V, Cohen Y, Meron M, Tsipris J, Naor A, et al Use of thermal and visible imagery for estimating crop water status of irrigated grapevine. Journal of Experimental Botany, 2007; 58(4): 827.

[20] Raza S E A. Registration of thermal and visible light images of diseased plants using silhouette extraction in the wavelet domain. Pattern Recognition, 2015; 48(7): 2119-2128.

[21] Kovesi P. Phase congruency detects corners and edges. In Australian Patt. Recog. Soc. Conf. DICTA. Sydney WA, 2003; pp.309-318.

[22] Lowe D. Distinctive image features from scale-invariant key points. International Journal of Computer Vision, 2004; 60(2): 91-110.

[23] Bay H, Ess A, Tuytelaars T, Goola L V. SURF: Speeded-Up Robust Features (SURF), Computer Vision and Image Understanding, 2008; 110(3) 346-359.

[24] Chen F, Wang R. Fast RANSAC with preview model parameters evaluation. Journal of Software, 2005; 16(8): 1431-1437. 